\title{
Mine planning subject to prepared ore reserves rationing
}

\author{
Kanay Rysbekov, ${ }^{1, *}$, Ayan Toktarov ${ }^{1}$, Tursyn Kalybekov ${ }^{1}$, Serik Moldabayev ${ }^{1}$, Timur \\ Yessezhulov $^{1}$, and Gulnara Bakhmagambetova ${ }^{1}$ \\ ${ }^{1}$ Satbayev University, 050013, Almaty, Satpayev Str., 22a, Republic of Kazakhstan
}

\begin{abstract}
This article deals with production planning in the context of providing technology at each mining stage with developed and ready-tostoping reserves. In order to address the problem, the ore body is represented by a geological block model. Numerical data is used to represent the attributes of each block, such as mass, density, ore grade, rock type. The mining plan provision with reserve standards on the degree of reconnaissance for production is reduced to the optimization task solution. The main condition for ensuring the planned production productivity of the mine is to provide the minimum necessary developed reserves. In the proposed mathematical model, it is taken into account by one of the objective function's terminators for solving the set task. As the results of the calculations have shown, such a scheduling ensures approach that there is developed ore's sufficient amount for at least 6 months at the beginning of each period, which is a clear advantage of the proposed model.
\end{abstract}

\section{Introduction}

Establishment of developed and ready-to-stoping reserves' optimal values during mineral deposits exploitation contributes to the creation of favorable conditions for their reasonable development [1]. The provision of the required volumes in terms of extracted ores' quantity and quality depends on the number of ready-to-stoping reserves available in the developed elementary extraction units (EEU): panels, blocks, sections, etc., Forming of production reserves is necessary in order to achieve these goals. The specified calendar volume of production and the efficiency level of the applied technological schemes have support in reserves.

In open mining, a part of ore reserves are considered developed if easily available at the beginning of the initial production processes planned period: drilling, blasting, mechanical loosening [2].

The task solution of the problem of degree of reserves reconnaissance is to determine the optimal sequence of reserve extraction EEU when planning ore body development with open as well as with underground mining. The ore body consists of several thousand or millions of blocks, respectively the mining planning models for such a structure are very complex, resulting in three-dimensional combinatorial linear tasks.

\footnotetext{
*Corresponding author: k.rysbekov@satbayev.university
} 
Such optimization tasks in mining practice are considered for economic assessment and mining operations planning at almost all production technological stages. Net present value (NPV) is considered the optimality criterion when planning the block development sequence. Planning is intended to find the optimal production sequence within certain final boundaries with established production capacities (in quantity and quality). The common practice of setting and solving these problems is to describe the ore body by constructing a three-dimensional block model (Figure 1), so the mining sequence planning task is also known as the block planning task [3].

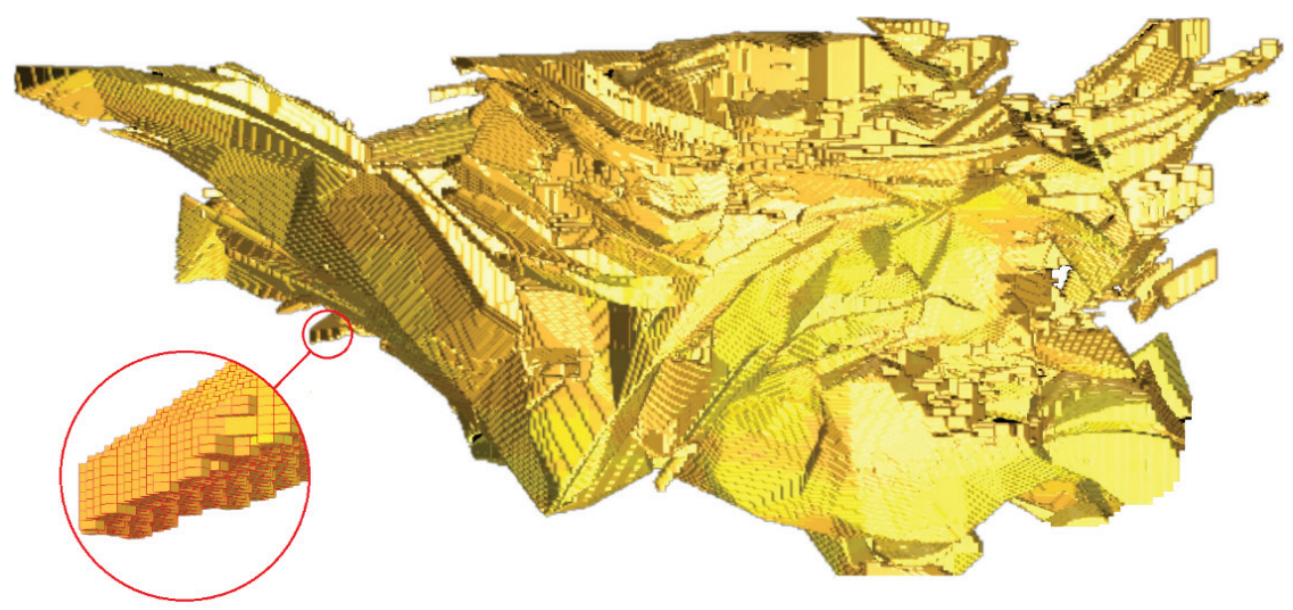

Fig. 1. Digital block model of ore body.

On the open mining operations example in solving the block planning task, the approach based on dividing the pit mining into separate stages with establishment for each stage of its optimal contours using the algorithm proposed by Lerchs and Grossman (1965) [4] is preferred. In the subsequent improvements and many interpretations of this method from various authors modified the optimization classical problem with different variants and combinations of constraints and variables to solve the planning problem [5-12]. The resulting tasks are solved using standard integer programming IP algorithms.

The task is to form a plan for the mining operations development. The classical optimization model of mine planning by integer programming methods solves it. In the proposed version of the solution, there are added restrictive conditions for readiness of ore reserves in blocks for development. The number of stocks prepared for drilling, blasting, mechanical loosening characterizes these conditions.

\section{Methods}

Mining planning uses extraction units' models that contain information on the ores minerals content and other technological properties in their structure. The annual planning task solution is based on tools of cutback interactive forming with automatic determination of ore and stripping volume and quality indicators. The tool work is based on the use of the quarry current and final position's skeleton models, as well as the ore bodies block model (Figure 2).

Geometrical description of deposit and qualitatively homogeneous zones is the initial information for the task. This information is generated based on the field geomerization results performed directly by the geological and surveying service of the mine. Points coordinates' arrays that form discrete linear-coordinate models of ore bodies and individual sections represent this information in the database. 


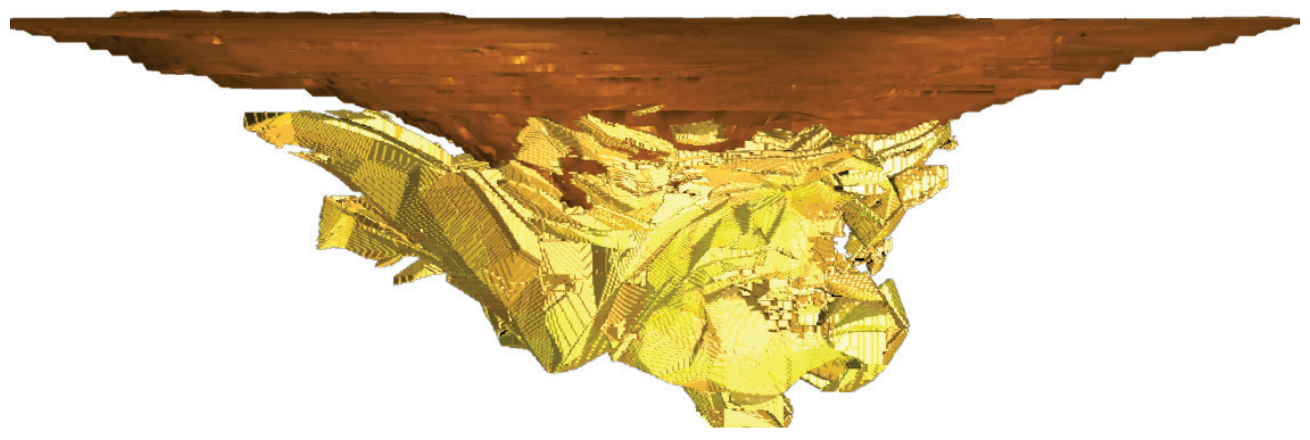

Fig. 2. Digital model of field open mining.

The stage of geometric objects modeling provides a discrete volume-coordinate model formation of the mineable ore section in the form of EEU list with their spatial position and geometric characteristics indication. At the next stage, parameters of EEU development are calculated based on duration and interlinkages simulation in time of technological processes for ore reserves reproduction and extraction in extraction units.

Planning of mining operations development with digital technologies carried out through the quarry field spatial modeling, within which limits possible choices for deposit reserves development will considered. For mining operations development automated planning, digital simulation models of geometric contours of the following objects created:

- ore bodies' contours limited by established industrial conditions of commercial components content;

- uniform zones contours characterized by uniform qualitative features, for example, useful component content, mineral composition of ore, harmful impurities content, etc.;

- zones contours according to mining technical conditions;

- extraction sections contoured by advance workings within the ore body contour;

- elementary extraction units - benches, panels, blocks, cameras, etc.

Each block characterized by its metal content, density, lithology, and other relevant features, which derived from geostatistical evaluation techniques specifically designed to address the spatial nature of the mineralization.

The priority between blocks is one of the most important constraints sets as the extraction process runs from the surface to the mineralization bottom. The Law of Proportional Development of Mining Works applies to each block in the model: it is impossible to access this block at a certain time, if the blocks that are above, have not already been removed, or before the opening and advance workings have not been driven.

Ensuring inventory standards by degree of reconnaissance reduced to solving the optimization task. Here the condition of providing the minimum necessary developed reserves to ensure the planned production productivity of the mine ought to be taken into account by one of the limiters. It is also necessary to introduce new variables representing the ready-to-stoping blocks and the corresponding new constraints described below.

The mathematical integer-programming model under consideration is a continuation of classical models, with the introduction of new variables and limiters that denote blocks of developed ore reserves.

Let B - be a set of blocks, $b$ - be the number of blocks, $i$ - be the elementary block (one of the set). Each block has a certain number of attributes, such as mass and ore grade; these attributes allow to determine economic value of each block in set B. Assume that for each block $i$ known mass $m_{i}$ (tons), grade of ore with $c_{i}(\%$, estimated grade of an orebody) and net discounted income given by $f_{i}^{t}$ (\$, dollars) if block $i$ is sent to the factory in period 
$t$ (months), and $o_{i}^{t}(\$$, dollars) if block $i$ is shipped to empty rocks dumps in period $t$ (months).

This model also addresses the issue of mined rock mass shipment to the factory or to the draw rock dumps depending on the boundary value. For each period $t$ (months) there are limits on the amount of digged material ( $d^{t}$, tons) and on the amount of ore sent for processing ( $p^{t}$, tons). At the same time, at each development stage the minimum standards of the developed ore reserve $s r^{t}$, (tons), available to dredging from the beginning of the following stage have to provide. For this purpose, we will limit all blocks from participation in formation of the required standard reserves and we will include only ore blocks, commercial component content in which is higher than certain boundary value $c_{b}(\%)$. To do this, you must enter additional parameters:

$$
\text { if } c_{i} \geq c_{b} \text {, then } \bar{c}_{i}=c_{i} \text {, differently } \bar{c}_{i}=0 \text {. }
$$

$\bar{c}_{i}$ - contents in the ore blocks participating in the required standard reserves formation.

This is necessary in order to give the model flexibility in selecting the useful component content, while preventing the inclusion of low-grade blocks to meet the quality requirements of the produced ones.

The model uses three kinds of binary variables.

The first kind is a variable to denote stocks of blocks shipped after mining to a factory for enrichment:

$$
\begin{aligned}
& \text { if block } i \text { is extracted and enriched in period } t \text {, } \\
& \text { then } d p_{i}=1 \text {, differently } d p_{i}=0
\end{aligned}
$$

The second type of variable describes the rock mass of the worked unit, which shipped to the empty rock dump:

if unit $i$ is removed and shipped to empty rock dump in period $t$,

$$
\text { then } e r_{i}=1 \text {, differently } e r_{i}=0 \text {. }
$$

Moreover, the third type of variable used to determine which blocks (developed reserves) are available for production:

if block $i$ is available (prepared) in period $t$,

$$
\text { then } d r_{i}=1 \text {, differently } d r_{i}=0 \text {. }
$$

The objective function of the model is to maximize net discounted income (NPV):

$$
\operatorname{Max} \sum_{i \in B} \sum_{t=1}^{T}\left[f_{i}^{t} d p_{i}-o_{i}^{t} e r_{i}\right]
$$

the following are the limiters for this function according to the task:

$$
\begin{gathered}
\sum_{t=1}^{T}\left(d p_{i}+e r_{i}\right) \leq 1 \text { for each } i \in B \\
d r_{i} \leq d p_{i}^{t+1} \text { for each } i \in B, t \in\{1, \ldots T-1\}
\end{gathered}
$$




$$
\begin{gathered}
\sum_{i \in b} m_{i} \bar{c}_{i} d r_{i} \geq d r^{t} \text { for each } t \in\{1, \ldots T-1\} \\
d p_{i}, e r_{i}, d r_{i} \in\{0,1\} \text { for each } i \in B, t \in\{1, \ldots T\}
\end{gathered}
$$

$T$ - time horizon (number of periods).

The objective function (1) represented to maximize the total discounted cash flow. The boundary function (2) means that it is not possible to select two different values for the block, that is, the block can accept only as one of the specified values - shipment for processing or for empty rocks dump. Constraint (3) indicates that the prepared block must be developed and shipped to the factory in the next step. Limitation (4) provides a condition for minimum developed reserves according to the established standard (in terms of extracted metal units), which must be available for production from the beginning of the next stage. Constraint (5) indicates the properties of variables used in the model. The model also took into account the standard limiters for the classical model, which set the upper boundary for ore production for each stage.

\section{Results and discussion}

The level of organization of the ore flow system depends on the created reserves of extraction units' capacity and the order of their development, which leads to some result in the form of mine productivity increase. As a result, the task of ore flow systems formation based on their optimal organization related to determination of economically profitable reserves of developed and ready-to-stoping reserves' capacity [1].

The task discussed in this article is to develop a block development schedule similar to a classical task, but with the inclusion of additional limitations - to ensure a sufficient number of developed and ready-to-stoping ore reserves in blocks that are readily available at the start of each planned development phase. Visualization of the implementation results of the obtained mathematical model and their comparison with the standard classical model shown in Figure 3. Here, $a$ ) is the standard optimization model of the Quarry Work Planning Board without taking into account the reserves of degree of reconnaissance; $b$ ) - a proposed planning model for the quarry mining sequence, taking into account the standards of developed and ready-to-stoping reserves. By analyzing the obtained graphs of the quarry blocks extraction sequence according to the development stages following conclusions can be drawn. First of all, it can be seen that when planning the reserves development schedule taking into account the standards of reserves development, the geometric shape of the bottom part of the quarry has a larger horizontal surface, hence a larger area. Accordingly, the reduction rate of mining operations in embodiment $b$ ) is lower than the deepening rate of quarry $a$ ). However, the most interesting property of the obtained geometrical shape is that quarry $b$ ) has more available ore reserves, and this is a significant advantage of this model in terms of the equipment capacity operation ease, as well as stability and safety of technological operations.

Each block in the obtained graph contains the following information: stage and years of development, content and grade of processed blocks, mass of ore blocks developed at the current stage and ready for extraction at the next stage of development. The schedules are similar in both cases, and they both provide roughly the same amount of production, but the reserve volumes of developed and ready-to-stoping reserves of blocks, and accordingly the commercial components content, vary greatly. Due to different rates of mining operations reduction, in the calendar plan of variant $b$ ) at each stage of mining the amount of produced ore less to $5-7 \%$ than in variant $a$ ). However, option $(b)$ ensures that there is a sufficient amount of developed ore for at least 6 months at the beginning of each period, which is a clear advantage of the proposed model. 
a)

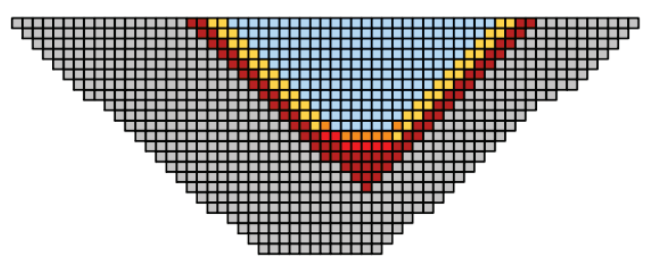

Development phase: $\square$ mined blocks at phase I

mmined blocks at phase II

prepared at phase I and

$\checkmark$ will be extracted at phase II ore reserves

mmined blocks at phase III

„ prepared at phase II and

will be extracted at phase III ore reserves b)

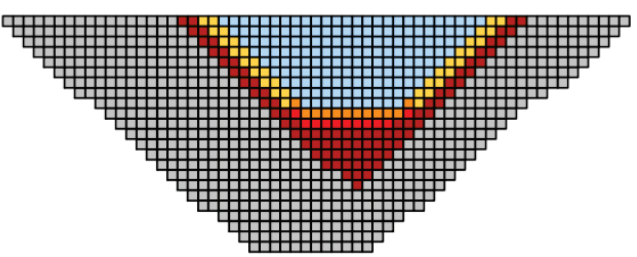

Fig. 3. Results of mining development modelling: $a$ ) standard planning approach; $b$ ) proposed model taking into account standard reserves of developed and ready-to-stoping stocks.

According to this model, once the steps planned, the work-up calendar adjusted so that there is always enough reserves ready-to-stoping to ensure production and processing processes within a few months. However, the strategic optimization model cannot account for unexpected technological failures that may affect production. Although this task can be solved by introducing in the calculations a reserve factor, determined by experience, work individually for each deposit based on the specific conditions of their development, which can be the subject of further research to supplement and improve the optimization model.

\section{Conclusions}

The model considered, due to its inclusion of additional requirements and restrictions on mandatory unit reserves, is inferior in the optimality of the decisions taken in maximum profit terms, compared to similar optimization models, which do not take into account the needs in developed ore reserves. However, the geometric essence of these solutions obtained during the mathematical model implementation shows relatively better operational capabilities from the point of view of the reserves development regularity and rhythmicity in the blocks.

Planning of mining work schedules taking into account the standards on the degree of reconnaissance of reserves for stoping:

- ensures execution of production plans at the enterprise rhythmic operation;

- provides stable quality of ore flows due to sufficient number of different grades blocks for averaging purposes;

- allows taking into account specifics of mining-geological and mining technical conditions, at the expense of reserve factor;

- generally promotes the most rational use of mineral resources.

The proposed method of mining planning forms almost optimal schedules taking into account the following operational parameters: production capacity by rock mass, minimum required production volume, number of new extraction units, averaging, production speed, continuity and production sequence.

Article is prepared on the project of program and target financing of the Ministry of Education and sciences of the Republic of Kazakhstan 2018/BR05235618 


\section{References}

1. Kalybekov, T., Rysbekov, K.B., Toktarov, A.A., Otarbaev, O.M. (2019). Underground mine planning with regard to preparedness of mineral reserves. Mining informational and Analytical Bulletin, (5), 34-43. doi: 10. 25018/ 0236-1493-2019-05-0-34-43

2. Instructions for establishing and accounting for uncovered, prepared and ready-toextraction mineral reserves at mining enterprises of the Ministry of ferrous metallurgy of the USSR. (1974). VIAGEM, Belgorod, $39 \mathrm{p}$

3. Caccetta, L. (2007). Application of optimisation techniques in open-pit mining. Handbook of Operations Research in Natural Resources. Weintraub, A., Romero, C., Bjørndal, T., Epstein, R. (eds.). Springer, New York

4. Lerchs, H., Grossmann, I. (1965). Optimum design for open pit mines. CIM Bulletin, (58), 47-54

5. Amankwah, H., Larsson, T., Textorius, B. (2014). A maximum flow formulation of a multi-period open-pit mining problem. Operational Research, (14), 1-10

6. Chicoisne, R., Espinoza, D., Goycoolea, M., Moreno, E., Rubio, E. (2012). Anew algorithm for the open-pit mine production scheduling problem. Operations Research, (60), 517-528

7. Tabesh, M., Askari-Nasab, H. (2011). Two-stage clustering algorithm for block aggregation in open pit mines. Mining Technology, (120), 158-169

8. Zhang, M. (2006). Combining genetic algorithms and topological sort to optimize openpit mine plans. Proceedings of the 15th International Symposium on Mine Planning and Equipment Selection (MPES). Cardu, M., Ciccu, R., Lovera, E., and Michelotti, E. (eds.). FIORDO S.r.l. Torino, Italy, 1234-1239

9. Kuzmenko, S., Kaluzhnyi, Ye., Moldabayev, S., Adamchuk, A., Toktarov, A. (2019). Optimization of position of the cyclical-and-continuous method complexes when cleaning-up the deep iron ore quarries. Mining of Mineral Deposits, (13), 104-112

10. Moldabayev, S., Sultanbekova, Z., Toktarov, A. (2017). Management reserves of mining operations mode in open pit mining of steeply dipping mineral occurences. International Multidisciplinary Scientific GeoConference Surveying Geology and Mining Ecology Management, SGEM, (17), 519-528

11. Moldabayev, S., Sultanbekova, Zh., Aben, Ye., Rysbaiuly, B. (2014) Ways to achieve the optimal schedule of the mining mode of double subbench mining. Progressive Technologies of Coal, Coalbed Methane, and Ores Mining. 35-40. https://www.taylorfrancis.com/books/e/9780429226946/chapters/10.1201/b17547-8

12. Kalybekov, T., Yunussov, R., Rysbekov, K.V., Soltabayeva, S.T. (2018) Control of reserves readiness and quality characteristics of ore in open pit mining. The $25^{\text {th }}$ World Mining Congress 2018. Proceedings. Open-Pit Minings. Astana. 220-226 